\title{
Why does real-time information reduce energy consumption?
}

\author{
John Lynham ${ }^{\mathrm{a}, \mathrm{b}}$, Kohei Nitta ${ }^{\mathrm{c}}$, Tatsuyoshi Saijo ${ }^{\mathrm{d}}$ and Nori Tarui ${ }^{\mathrm{a}, \mathrm{b}^{*}}$
}

October 2015

\begin{abstract}
A number of studies have estimated how much energy conservation is achieved by providing households with real-time information on energy use via in-home displays. However, none of these studies tell us why real-time information changes energy-use behavior. We explore the causal mechanisms through which real-time information affects energy consumption by conducting a randomized-control trial with residential households. The experiment attempts to disentangle two competing mechanisms: (i) learning about the energy consumption of various activities, the "learning effect", versus (ii) having a constant reminder of energy use, the "saliency effect". We have two main results. First, we find a statistically significant treatment effect from receiving real-time information. Second, we find that learning plays a more prominent role than saliency in driving energy conservation. Our findings support the use of energy conservation programs that target consumer knowledge regarding the energy use of different devices and activities.
\end{abstract}

Keywords: Energy efficiency; Energy conservation; Real-time information; Field experiment JEL Codes: D03; D12; Q41; Q48

\footnotetext{
${ }^{a}$ Department of Economics, and ${ }^{b}$ UHERO, University of Hawai 'i, 96822 Honolulu, U.S.A., ${ }^{c}$ Chair of Economic Theory, University of Erlangen-Nuremberg, Germany, ${ }^{\mathrm{d}}$ Institute of Economic Research, Hitotsubashi University, Japan. * Corresponding Author: 2424 Maile Way, Saunders 518, Department of Economics, University of Hawaii at Manoa, Honolulu, HI 96822 USA. Email: nori@ hawaii.edu. Phone: +1-808-956-8427.
} 


\section{Introduction}

Reducing energy use is now a major policy goal in most countries. In-home displays (IHDs) have received increasing attention as a potential tool to encourage energy conservation. IHDs are designed to give electricity consumers detailed, real-time information about electricity use and cost. A number of studies have estimated how much energy conservation is achieved by providing households with IHDs (as opposed to monthly electricity bills, which provide information about aggregate usage and charges). However, none of these studies tell us why IHDs change energy-use behavior. In other words, what are the causal mechanisms linking these devices to outcomes? Is it because these devices update consumers' beliefs about how much power different appliances use? Is it because IHDs make energy use more salient as residents are constantly reminded of their energy consumption? While the first hypothesis implies the presence of a "learning effect," the second hypothesis implies the presence of a "saliency effect".

This paper describes an initial attempt to disentangle the mechanisms through which real-time information affects energy consumption by conducting a field experiment. Understanding these mechanisms may have large policy implications. For example, if learning about the energy consumption of different appliances is the main reason why real-time information induces energy conservation, then this advocates for a particular suite of energy policies (e.g., educational outreach, labeling electronic appliances with their energy consumption, etc.). On the other hand, if the real benefit of having IHDs is as a constant "nudge" or reminder, then this advocates a very different set of policies (e.g., finding the best medium to remind consumers about their energy consumption, exploring the optimal frequency of reminders). In 
addition, understanding why IHDs work in a real field setting should help in the design of future IHDs.

We present the results of a randomized-control experiment with 65 residential households in a condominium complex in a large U.S. city (Honolulu). In the experiment, we randomly assign households into one control and two treatment groups. After installing data-collecting devices for each household, the control group has their energy consumption monitored but does not receive an IHD during the experimental period. The two treatment groups have data-collecting devices installed, and then receive IHDs but with one critical difference. The "Continued" treatment group has access to their IHDs for the entire duration of the experiment, while the "Discontinued" treatment group loses access to their IHDs in the last month of the experimental period. By comparing how electricity use changes over time and across the three groups, we are able to (i) estimate the amount of electricity conservation attributable to IHDs, and (ii) disentangle whether learning about energy use is sufficient to sustain energy conservation or whether having a constant reminder of energy use is also necessary.

Although our sample size is small, our simple experimental design illustrates lessons that are extremely relevant to the future adoption of IHDs. In line with previous studies, we observe an average reduction in electricity consumption of up to $11 \%$, depending on the time of day. This effect depreciates over time (again in line with previous studies) and the reductions in electricity usage appear to be driven primarily by learning and not by saliency effects. The rest of this paper sets out to explain these results in more detail. Section 2 provides a brief literature review, Section 3 presents the experimental design, Section 4 summarizes our main findings, and Section 
5 concludes.

\section{Literature Review}

A number of studies have used field experiments to better understand energy conservation programs (see Abrahamse et al., 2005 for a review). An obvious method to achieve energy conservation is to provide economic incentives to reduce energy consumption (Winett et al., 1978; Midden et al., 1983; Petersen et al., 2007; Mizobuchi and Takeuchi, 2012). Another approach is to estimate how detailed information on power use can contribute to energy conservation (Sexton et al., 1989; Wood and Newborough, 2003; Delmas et al., 2013; Asensio and Delmas, 2015). For example, Matsukawa (2004) measured the effect of information (provided by a continuous-display, electricity-use monitoring device) on residential electricity demand in a field experiment with 319 randomly selected households. Subjects were randomly assigned to either a control or treatment group. Only the treatment group members had free provision and installation of monitors. Results demonstrated that monitor usage contributed to a modest reduction in electricity consumption. In terms of possible causes for the small effect, the author argues that subjects might have found the monitors difficult to operate and that updates in electricity use were not frequent enough (subjects received hourly not real-time information). In a recent intriguing study, Delmas and Lessem (2014) find no effect of private real-time information on electricity use in UCLA residence halls, unless this information is coupled with publicly visible information.

Faruqui et al. (2010) review a number of pilot programs worldwide that focus on the 
energy-conservation impacts of IHDs as well as alternative electricity rate structures. Among the programs that tested the effect of IHDs on electricity consumption (where the test period ranged from three months to two and a half years), the average reduction in energy use was $7 \%$, and the largest reduction observed was $13 \%$. Fischer (2008) reviews a number of studies on IHDs, most of which have been published in the psychology literature. IHDs tend to achieve energy conservation gains between 5 and 12\%. Houde et al. (2013) find average reductions of 5.7\%, but this effect only lasts for four weeks at statistically significant levels. Overall, the literature tends to find that IHDs encourage people to reduce their electricity usage by about 5 to $10 \%$ but this effect tends to decline over time.

This observed reduction in electricity usage is often attributed to IHDs helping consumers to learn about the energy cost of different activities. Consumers often lack sufficient information about how much energy different appliances use and how much they cost to run. ${ }^{1}$ Even when information is available, processing detailed information about the energy costs of each appliance and figuring out optimal electricity use could be challenging and costly for consumers. The problem is further compounded when consumers only receive aggregate monthly electricity use data. Introducing IHDs may enable consumers to make more optimal energy use decisions. A common assumption in the energy literature is that optimal energy use implies less energy use, i.e., cognitive biases cause consumers to use too much not too little energy. There is some evidence to support this assumption: a recent study (Attari et al., 2010) of an internet-based survey finds that people tend to underestimate the energy used by household appliances (e.g., air conditioners) and the amount of energy savings from efficiency-enhancing activities (e.g.,

\footnotetext{
${ }^{1}$ Newell and Siikamäki (2014) examine the effect of energy conservation labeling when households purchase electronic devices. They found that information on the device's costs had more of an effect than information on energy use in $\mathrm{kWh}$ or carbon emissions.
} 
switching to high-efficiency light bulbs). Thus, real-time information may reduce energy use through the process of consumers learning information that allows them to re-optimize.

Why does the effect of real-time feedback tend to decay over time? A number of studies have shown that consumers change their behavior upon receiving new information but the behavioral change may not persist over time (e.g., Haselhuhn et al., 2012, Allcott and Rogers, 2014). Most studies interpret this change in behavior as a decaying learning effect. For example, in the context of late payment fees on credit cards, Agarwal et al. (2013) estimate that "the learning effect of a fee payment effectively depreciates at a rate of between 10 and 20 percent per month" (p.3). Hence, learning changes short-term behavior but it may not lead to formation of long-lasting habits.

A separate strand of the literature has explored the importance of making information more salient. Yates and Aronson (1983) found that consumers attach disproportionate weight to more psychologically vivid and observable factors, often called the saliency effect. Fischer (2008) reviews IHD projects that vary the frequency with which consumers receive information about electricity use. She finds that more frequent feedback results in larger energy savings. This is suggestive of a saliency effect, but could also be explained by learning. There has been little work to distinguish whether one mechanism is more dominant than the other. Dietz (2010) argues that "many [policies] to promote household energy efficiency are not based on an understanding of how residents think about and make decisions regarding energy efficiency." As Gillingham et al. (2009) note, "the empirical literature testing behavioral failures specifically in the context of energy decision making is very limited." In the context of energy conservation, the 
mechanisms through which consumers reduce energy use when real-time information is provided have not been explored experimentally. ${ }^{2}$ This paper is a first step in that exploration.

\section{Experimental Design}

\subsection{Hypothesis Tests}

This research aims to identify the mechanisms through which real-time information reduces energy consumption. The experiment consists of three periods: Periods 0,1 , and 2 , each lasting for about 30 days. Electricity measurement devices are installed in all apartments at the beginning of Period 0. Period 0 is the baseline period with no IHDs for all groups. Our experimental design has one control and two treatment groups: the control group receives no real-time information about their energy consumption during the experimental period (just their usual monthly bill), whereas the households of the two treatment groups receive IHDs (i.e., real-time information) at the beginning of Period 1. At the beginning of Period 2, IHDs are then removed from the Discontinued treatment group, while the other treatment group (the Continued treatment group) retains IHDs for the duration of Period 2.

Ex ante, we might wonder if the length of Period 1 (30 days) will be sufficient to induce learning and behavioral change? In previous studies on the effect of feedback on residential

\footnotetext{
${ }^{2}$ In a recent experimental paper, Jessoe and Rapson (2014) explore how households with IHDs respond to electricity price changes relative to households without. Households with IHDs are more responsive to price changes and survey evidence suggests that this is due to learning and not saliency. The focus of Jessoe and Rapson (2014) is on differential price responses and not on why IHDs change behavior. Our experimental design is unique in that we observe behavior after IHDs are removed. Interestingly, both studies suggest that the learning effect is more important than the saliency effect.
} 
electricity consumption, the length of the treatment periods ranged from a few days to a few years (Abrahamse et al., 2005; Faruqui et al., 2010). Investigating the impact of home energy reports, Allcott and Rogers (2014) find that "consumers reduce electricity use markedly within days of receiving each of their initial reports, but these immediate efforts decay at a rate that might cause the effects to disappear after a few months if the treatment were not repeated" (p.3004). Houde et al. (2013) find that the treatment effect of real-time feedback declines and becomes insignificant starting the fifth week after the treatment. Thus, the existing literature suggests that the length of Period 1 (30 days) should be sufficient to allow for behavioral changes but the energy-conservation effect may weaken during Period 2 (60 days).

Our experimental design allows us to identify the primary effect of receiving real-time information. Therefore, our first testable hypothesis is the following:

Hypothesis 1: Real-time information reduces residential households' energy consumption.

[Table 1 here]

We will test this hypothesis by comparing the control group and the treatment groups' electricity use before and after receiving the devices, i.e., Period 0 compared to Periods 1 and 2. Table 1 summarizes our experimental design and the potential effects of IHDs. "L1" ("L2") refers to learning due to IHDs in Period 1 (2) while "S" refers to the saliency effect of IHDs - the latter is present only when the household has access to an IHD. "RL1" refers to the remaining learning effect from Period 1 that may be present in Period 2. Hypothesis 1 tests $\mathrm{L} 1+\mathrm{S}=\mathrm{RL} 1+\mathrm{L} 2+\mathrm{S}=0$. 
Next, we move to identify why people reduce their energy consumption. To test this deeper question, we examine behavior over three experimental periods. Our second testable hypothesis is the following:

Hypothesis 2: Access to real-time information does not reduce residential households' energy consumption once access is discontinued.

In order to test Hypothesis 2, we will examine if the change in the electricity consumption from Period 0 to Period 2 is different for the control group and the Discontinued treatment group. Any difference would come from behavior changes induced by the IHDs that persist once the IHDs have been removed. We have labeled this the remaining learning effect (RL1) in Table 1. In addition, we will use results from an exit survey to further test whether RL1 is due to acquiring new knowledge about the electricity usage of different appliances. In particular, we investigate whether the two treatment groups have more accurate estimates of various appliances' energy usage than the control group, and whether the Discontinued treatment group is still just as informed as the Continued treatment group at the end of Period 2.

In addition to testing the strength of the learning effect, we wish to test the strength of the saliency effect. Do IHDs have an effect on consumption because they are constantly reminding households about their energy use? Our third testable hypothesis is the following:

Hypothesis 3: Even in the presence of a learning effect, constant access to real-time information causes additional energy savings. 
In Period 2, the households in the Discontinued treatment group do not have IHDs and thus have no access to real-time information. In order to test Hypothesis 3, we will examine if the change in electricity consumption from Period 0 to Period 2 is different for the two treatment groups (i.e., if $\mathrm{L} 2+\mathrm{S}=0$ ). If there is no difference, Hypothesis 3 is rejected: assuming L2 is nonpositive, the saliency effect is deemed to be zero if $\mathrm{L} 2+\mathrm{S}=0$ (see Table 1$){ }^{3}$ An important caveat is that, if $\mathrm{L} 2+\mathrm{S} \neq 0$, we will not be able to identify whether the difference between the Discontinued and Continued treatments comes from learning that occurs in Period 2 (L2) or from saliency (S).

\subsection{Experimental procedure}

In order to conduct the proposed field experiment, we recruited households at a faculty condominium complex in Honolulu to voluntarily participate in the experiment. In order to give the residents incentives to participate in the experiment, the residents were notified in advance that they would be able to keep the installed IHDs free of charge after the end of the experiment. Eventually, 65 households voluntarily participated in the experiment. Unfortunately, the devices only recorded accurate data over the entire experimental period in 58 out of the 65 households. ${ }^{4}$ In terms of housing units, they are all fairly homogeneous: virtually all units have an identical 2-bedroom floor plan, identical electricity circuits, and identical lighting fixtures. All households have the exact same basic appliances: oven, refrigerator, water heater, etc. Based on survey responses, we found that almost all households have a television set and desktop computer.

\footnotetext{
${ }^{3}$ Note that, based on the existing literature, we are assuming that the learning and saliency effects are nonpositive $(\leq 0)$, i.e., they reduce energy consumption if they have any effect.

${ }^{4}$ One subject in the Continued treatment group moved out during the experiment - around the end of Period 1 - so we only use this household for the testing of Hypothesis 1.
} 
Households pay their electricity bills by themselves. As stated earlier, we randomly assigned these households to three groups: one control and two treatments. We do not have data on peer interactions among participants. On the one hand, interactions between treatment-group households and control-group households may decrease the treatment effect. On the other hand, interactions among treatment-group households might amplify the treatment effect of IHDs. Therefore, spillover effects could potentially enhance or weaken the measured treatment effects. ${ }^{5}$

Table 2 summarizes the description of our subject households based on survey responses. The average age in a household was 33.53, and each household had an average of 2.69 people (including 0.86 children). In each household, there were 1.48 income earners on average. Each household was occupied approximately 16.19 hours per day on weekdays and 17.79 hours per day on weekends. There were no statistically significant differences between treatment groups in terms of these important determinants of energy use. This gives us confidence that our random treatment assignment was successful. There may, of course, be unobserved differences between households so all of our regression models include household fixed effects.

We used two main devices for this experiment: an electricity measurement device and an IHD. The electricity measurement device was installed in each unit's circuit breaker panel at the beginning of the experiment, when we also conducted an initial survey. After we confirmed that the recording devices were working, we distributed IHDs to the two treatment groups. IHDs

\footnotetext{
${ }^{5}$ One of our exit survey questions for the participating subjects provides supporting evidence that spillovers across the control and the two treatment groups were limited. To the question "Do you think being in this project reduced your energy consumption?" less than $45 \%$ of the control-group subjects answered yes while more than $75 \%$ of the treatment-group subjects answered yes.
} 
provide users with real-time information about their energy consumption (in both $\mathrm{kWh}$ and in dollars per hour). ${ }^{6}$ The IHD is portable so that households using it can easily walk around, switch various devices on and off, and identify how much electricity various devices consume. ${ }^{7}$ Overall, the experiment lasted for approximately 90 days, depending on the exact date of device installation and final debriefing. There was minimal temperature, climatic, or precipitation changes over this three-month period.

\section{Analysis and Results}

\subsection{Treatment effects of access to real-time information}

First, we summarize the average electricity consumption by group and by period. Figure 1 presents average consumption per hour (normalized so that each treatment group consumes 1 unit in Period 0). In the control group, the average hourly consumption increases from Period 0 to Period 1, and then decreases from Period 1 to Period 2. Households in the Discontinued and the Continued treatment groups exhibit noticeably lower average consumption in Period 1. Consumption continues to decrease from Period 1 to Period 2 but only slightly for the Continued treatment group. Overall, both treatment groups reduce their consumption from Period 0 to Period 2 (8\% for Discontinued and 4\% for Continued).

Energy consumption and (therefore, saving) behaviors could be very different at different

\footnotetext{
${ }^{6}$ The IHD we used is marketed as the "TED 5000" by The Energy Detective (http://www.theenergydetective.com/).

7 The cost of using an IHD itself is extremely small (\$0.08 per month), so we assume that there is no significant difference between the control and treatments groups due to having the IHD plugged in.
} 
times of the day. Therefore, we also consider average hourly consumption in kWh by each treatment group in each period at different times of the day. We focus on four time periods: morning (6-10am), daytime (10am-6pm), evening (6-10pm), and night (10pm-6am). Table 3 presents average electricity consumption for these four time periods across treatments and across experimental periods. Most of the interesting changes in behavior occur when people are at home so we focus on those time periods (this is in line with the existing literature). We start with the morning, 6am-10am (see the left hand side of Figure 2). In the control group, the average consumption decreases slightly from Period 0 to Period 1, and then increases from Period 1 to Period 2 to a higher level than Period 0. In the Discontinued treatment group, the average consumption decreases noticeably from Period 0 to Period 1, then increases from Period 1 to Period 2, but is still lower than in Period 0. In the Continued treatment group the trend is the same: the average consumption drops dramatically from Period 0 to Period 1 , then rebounds from Period 1 to Period 2, but is still lower than in Period 0.

Next, we consider electricity consumption at the evening, 6pm-10pm (the right hand side of Figure 2). In the control group, the average consumption increases from Period 0 to Period 1, and then decreases from Period 1 to Period 2, to end up lower than Period 0. In contrast, in the Discontinued treatment group, the average consumption decreases from Period 0 to Period 1, and then decreases again from Period 1 to Period 2. In the Continued treatment group, the average consumption decreases from Period 0 to Period 1, and then decreases again from Period 1 to Period 2. Overall, both treatment groups reduce their consumption from Period 0 to Period 1, whereas the control group increases their consumption during this time frame. Both treatment groups have 9\% lower consumption in Period 2, relative to Period 1. 
Figures 1 and 2 certainly suggest that the IHDs have an effect on behavior during peak use periods. We now apply formal regression analysis to estimate the effect of having an IHD on electricity consumption. Let $C_{i h t}$ be household $i$ 's electricity consumption in hour $h$ on day $t$, and $C_{i t}^{p}$ be household $i$ 's average hourly electricity consumption in time period $p$ on day $t(p$ represents the morning (6am-10am), day time (10am-6pm), and so on). Table 4 presents the results from ordinary least squares (OLS) regressions estimating the following model:

$$
\log C_{i t}^{p}=\alpha+\beta I H D_{i t}+\gamma_{i}+\eta_{t}+\varepsilon_{i t}
$$

where the dummy variable $I H D_{i t}$ takes the value 0 for those who do not have IHDs and the value of 1 for those who have IHDs on day $t$. The other variables are household fixed effects $\left(\gamma_{i}\right)$, day fixed effects $\left(\eta_{t}\right)$ and a standard error term. Because all subjects in our sample live in the exact same area, weather variables are not considered here; the time fixed effect captures any weather differences across days. As for the time horizon, we consider all Periods and then just Periods 0 and 1 . We estimate our main regression separately for five different time periods during the day (morning peak, day time, evening peak, and so on) and for the whole day. By following Bertrand et al. (2004), we apply block bootstrapping in order to address possible serial correlation in the errors. Table 4 lists the estimated IHD effect, $\beta$, along with bootstrapped standard errors. The estimate is negative and statistically significant at the $10 \%$ level for the 6-10am time period (Periods 0 \& 1), and for the 6-10pm time period (all Experimental Periods). The other coefficients are insignificant. ${ }^{8}$ These results are almost identical to those found in the existing literature: significant effects in the morning and evening but mixed results overall.

\footnotetext{
${ }^{8}$ It should be noted that although the coefficient on the overall daily effect for all periods is not statistically significant, the power of the significance test on this coefficient is very small (16\%). This means it is very likely that we do not obtain a statistically significant effect even when there is an effect in reality. In other words, the failure to reject the null is underpowered.
} 
We also use hourly data directly to estimate the following specification:

$$
\log C_{i h t}=\alpha+\sum_{h=1}^{24} \beta_{h} I H D_{i h t}+\gamma_{i}+\mu_{h}+\eta_{t}+\varepsilon_{i t},
$$

where $\beta_{h}$ 's represent hour-specific treatment effects. As Table 5 indicates, the point estimates are less significant with hourly data (with a positive treatment effect at 5am). ${ }^{9}$ Nevertheless, the treatment effect is still significant at $6 \mathrm{pm}$.

Finding 1: Receiving real-time information leads to energy conservation during peak load hours (6am-10am and 6pm-10pm) but the overall daily effect is not statistically significant. ${ }^{10}$

The interpretation of this finding is as follows: through having the IHD, households were able to adjust their consumption down during times of the day when they were at home and using a large amount of electricity. In contrast, the results of the $10 \mathrm{pm}-6 \mathrm{am}$ and the $10 \mathrm{am}-6 \mathrm{pm}$ measurements imply that subjects did not adjust their consumption when they were out of the house or asleep. Therefore, we conclude that having an IHD has an effect on electricity usage in the morning and the evening. Hypothesis 1 is very weakly confirmed. We also ran the above regressions without household fixed effects but including a suite of controls. Our main results are unchanged. The only controls that turn out to be statistically significant are the number of people in a household (which is positively correlated with energy consumption) and a dummy variable for having a timer to switch a household's water heater on and off (which is negatively correlated with energy consumption).

\footnotetext{
9 We note that the regression results with hourly data in Table 5 indicate less precision than the results with period-of-day results in Table 4. For some households, electricity usage may not be stable at the hourly level though it may be at larger, multiple-hour time periods. Given our limited sample size, this may explain the difference between the results in Tables 4 and 5 .

${ }^{10}$ See footnote 8 for the power calculation.
} 


\subsection{Learning and saliency effects}

Next, we move to an investigation of the learning and saliency effects (Hypotheses 2 and 3). The learning hypothesis states that people reduce their energy usage when they receive real-time information due to better knowledge of how different devices consume electricity. According to the saliency hypothesis, people reduce their energy usage due to being constantly reminded about their consumption. One of the major findings in the IHD literature is that the effect of having an IHD declines rapidly over time. To allow for time-varying treatment effects, the following specifications include separate treatment dummy variables for different weeks over the duration of the treatment period.

First, we compare the control group and the Discontinued treatment group in Periods 0 and 2 (Hypothesis 2). For this purpose, we consider the following specification:

$$
\log C_{i t}^{p}=\alpha+\sum_{w=1}^{4} \beta_{w} D T_{-} W k(w)_{i t}+\gamma_{i}+\eta_{t}+\varepsilon_{i t}
$$

where the dummy variable $D T_{-} W k(w)_{i t}$ takes the value of 1 for those who had an IHD in Period 1 (i.e., those in the Discontinued treatment group) and are in Period 2 on day $t$ in week $w$, and the value of 0 otherwise. The upper panel of Table 6 indicates a large statistically significant effect for the 6am-10am time period. Having exposure to the IHD in Period 1 reduces consumption by $0.143 \log$ points $(13.3 \%)$ in the first week of Period 2. The treatment effects over all weeks are strongly jointly significant $(\mathrm{p}=0.001)$, but not in individual weeks after the 
first. ${ }^{11}$ This result indicates the time-decaying effect of IHDs. Therefore, we reject Hypothesis 2 regarding the complete absence of a learning effect.

The lower panel of Table 6 shows the OLS results of estimating the following model:

$$
\log C_{i t}^{p}=\alpha+\beta_{1} I H D 1_{i t}+\beta_{2 D} D T_{i t}+\beta_{2 C} C T_{i t}+\gamma_{i}+\eta_{t}+\varepsilon_{i t}
$$

where $I H D 1_{i t}$ represents the IHD treatment dummy for Period $1, D T_{i t}$ takes the value of 1 for those in the Discontinued treatment group in Period 2 on day $t$ and 0 otherwise, and $C T_{i t}$ is defined similarly for the Continued treatment group. Hypothesis 3 would suggest that $\beta_{2 C}<\beta_{2 D}$. While the estimate of $\beta_{1}$ is statistically significant, those of $\beta_{2 C}$ and $\beta_{2 D}$ are not. ${ }^{12}$ Again, this is consistent with the time-decaying effect of IHDs found in the literature. The estimates of $\beta_{2 C}$ and $\beta_{2 D}$ are not statistically different from each other.

Thus, the analysis above does not provide support for Hypothesis 3. In order to investigate the learning and saliency effects further, we attempt to take into account the decay of these effects by estimating the following model:

$$
\begin{aligned}
\log C_{i t}^{p}=\alpha & +\sum_{w=1}^{6} \beta_{1 w} I H D_{-} W k(w)_{i t}+\sum_{w=1}^{4} \beta_{2 D w} D T_{-} W k(w)_{i t} \\
& +\sum_{w=1}^{4} \beta_{2 C w} C T_{-} W k(w)_{i t}+\gamma_{i}+\eta_{t}+\varepsilon_{i t},
\end{aligned}
$$

where the dummy variable $I H D_{-} W k(w)_{i t}$ takes the value of 1 for those in the two treatment groups on day $t$ in week $w$ of Period 1 while $D T_{-} W k(w)_{i t}\left(C T_{-} W k(w)_{i t}\right)$ takes the value of

\footnotetext{
11 Power calculations on the significance of the Week 2 to Week 4 coefficients range from 15 to $39 \%$, suggesting that the failure to reject the null of no effect for these weeks is underpowered.

${ }^{12}$ The power of the significance test on the $\beta_{2 C}$ coefficient is $11 \%$. The power of the significance test on the $\beta_{2 D}$ is $19 \%$. Failure to reject the null is underpowered in both cases.
} 
1 for those in the Discontinued (Continued) treatment on day $t$ in week $w$ of Period 2, and the value of 0 otherwise. Parameter $\beta_{1 w}$ represents the weekly IHD treatment effects in Period 1 while $\beta_{2 D w}$ and $\beta_{2 C w}$ represent the weekly treatment effects in Period 2. We test for these effects by comparing all groups in Periods 0,1 and 2. Table 7 summarizes the results for 6am-10am and $6 \mathrm{pm}-9 \mathrm{pm} .{ }^{13}$ We find that, in the morning peak time, the treatment effect in Period $1(\mathrm{~L} 1+\mathrm{S})$ and the treatment effect for the Discontinued treatment group in Period 2 (RL1) are both statistically significant. Notably, having exposure to the IHD in Period 1 reduces consumption by $0.141 \log$ points $(13.1 \%)$ in the first week of Period 2. Jointly, the learning effects in Period 2 are statistically nonzero $\left(\mathrm{H}_{0}: \beta_{2 D w}=0\right.$ for all weeks in Period 2 is rejected with $p=0.02$ ) though the treatment effect is not individually significant in the later weeks of Period 2. ${ }^{14}$ This result again indicates the time-decaying effect of IHDs. The treatment effect for the Continued treatment group $(\mathrm{L} 2+\mathrm{S})$ is not precisely estimated and insignificant throughout Period 2. A joint test of significance on the weekly dummies for saliency effects fails to reject the null of no effect $(p=0.95)$. Overall, we fail to find strong support for the saliency hypothesis. Our results are therefore roughly consistent with $\mathrm{RL} 1<0$ but not $\mathrm{S}<0$.

Finding 2: We observe a declining learning effect but no clear saliency effect.

We also contrast saliency and learning effects by using the hourly data directly with the following specification:

\footnotetext{
13 The treatment effects are all insignificant in the other time periods.

14 For the coefficients on Weeks 2, 3, and 4, the power calculations are 26\%, 21\%, and 11\%, respectively. This again suggests that the failure to reject the null is underpowered.
} 


$$
\begin{aligned}
\log C_{i h t}= & \alpha+\sum_{w=1}^{6} \beta_{1 h w} I H D_{-} W k(w)_{i t}+\sum_{w=1}^{4} \beta_{2 D h w} D T_{-} W k(w)_{i t} \\
& +\sum_{w=1}^{4} \beta_{2 C h w} C T_{-} W k(w)_{i t}+\gamma_{i}+\mu_{h}+\eta_{t}+\varepsilon_{i t},
\end{aligned}
$$

where $\beta_{1 h w}, \beta_{2 D h w}$, and $\beta_{2 C h w}$ refer to hour-specific treatment effects by week in each period. Once again, the analysis with hourly data appears to be noisier than the analysis with average consumption over certain periods of the day. However, the results summarized in Table 8 largely resemble those in Table 7: the learning effect in Period 2 persists and is strongest in the first week. Again, the coefficients for the learning effects in Period 2 are jointly statistically different from zero. The treatment effect for the Continued treatment groups is statistically significant at 8am in the first week, but the estimates are imprecise for the rest of the weeks (with a positive, as opposed to negative, impact on energy consumption at 6am in Week 3 in Period 2).

\subsection{Learning versus saliency effects: supporting evidence from the exit survey}

As a further test of learning versus saliency, we conducted an exit survey with the participating households at the end of the experiment. The survey asked the subjects about the electricity consumption of various electric devices. It has been well documented that households are not well-informed about what share of their energy costs come from different sources (Chen et al., 2015): households tend to overestimate the cost of lighting, heating, and cooling but underestimate plug use. Figure 3 summarizes the results of our survey. Note that the Discontinued treatment group households have not had access to an IHD for over a month at the time of the exit survey, and the control group households have not received their IHD yet. The figure clearly demonstrates that households have learned something relative to the control group. 
Moreover, there does not appear to be any differences between the beliefs of the Continued treatment group and the beliefs of the Discontinued treatment group. For three out of the four devices, the Discontinued group is actually closer to the true energy consumption than the Continued group. Although this represents stated beliefs and not actual behavior, it strongly corroborates our earlier findings that the learning effect appears to be more important than the saliency effect. One obvious confounding factor in our experimental design is that we cannot strictly disentangle learning (updating beliefs) from habit formation (changing behavior and then sticking with it). The survey results strongly suggest that beliefs have changed as a result of the experiment. Furthermore, there is little support in our data for habit formation: energy-saving behavior does not persist over time but accumulated knowledge does appear to persist.

As discussed in Section 2, many studies find declining treatment effects from various forms of feedbacks. How can we reconcile our finding that the Discontinued group subjects appear to retain the knowledge acquired through learning but the learning effect is decaying over time? We do not have a clear answer to this question. However, consumers' endogenous inattention may provide an answer. Gabaix's (2014) model of utility maximization by inattentive consumers, who only take into account variables of first-order importance, may apply in the following way. When subjects receive the IHD at the beginning of the experiment, the real-time information may rank high among the set of variables used for decision-making. However, as weeks pass, the information from the IHD may claim lower priority for decision-making but can still be recalled in important situations, such as a survey conducted in your home by visiting researchers. This argument may also explain why the treatment effects become statistically insignificant for the Continued group subjects in Period 2. As speculated by Karlan et al. (2015) in a somewhat 
different context of sending reminders to consumers to make efficient savings decisions, repeated reminders may cause consumers to tune them out. An overall implication is that simple continuation of real-time feedback alone may not lead to sustained energy conservation. Another caveat is that, in estimating treatment effects, Type-II errors may be more prevalent in small samples such as ours than in larger samples (Leamer 1978, 100-120, Deaton 1997, 130-131). However, we note that the treatment effects of real-time feedbacks are statistically insignificant starting the fifth week of intervention with a much larger sample in Houde, et al. (2013). Therefore, in terms of the duration of the estimated treatment effects, our finding is in line with previous studies.

\section{Conclusion}

Building on the existing literature on IHDs, this paper explored the causal mechanisms behind the effect of receiving real-time information on electricity consumption. In particular, we attempted to disentangle whether the effect is because information enables households to learn about their energy consumption or if it is because displays make energy use more salient. The first main result of our experiment is that those who received real-time information about their electricity consumption reduced their consumption in the morning and the evening but not at other times of the day. However, the effect diminishes over time. In addition, we find supporting evidence that this effect is driven primarily by learning and not by saliency. This finding suggests that energy-conservation policies that target learning (e.g., educational outreach, labeling electronic appliances with their energy consumption) might be more cost-effective than the expensive process of installing in-home devices. 
Our study does not rule out the existence of saliency effects, but they do not stand out in our data. The issue may be that the IHDs we used did not sufficiently engage users, i.e. they were not salient enough to have an effect. ${ }^{15}$ Our findings also indicate that simple continuation of real-time information may not be as effective as monthly home energy reports. Clearly, real-time information is more effective in inducing learning about energy usage than a monthly report but this does not seem to induce habit formation and long-term energy conservation. Understanding the superior performance of monthly home energy reports relative to IHDs remains an important research question. Although there is little support in our data for habit formation, accumulated knowledge about the consumption of electric devices does appear to persist over time. Understanding why learning is not being translated into action will be critical to ensuring that large-scale introductions of IHDs are actually successful.

${ }^{15}$ Chen et al. (2014) present a novel experimental exploration of how to determine and improve user engagement with real-time information. 


\section{Acknowledgements}

This research was funded by a U.S. Department of Energy Workforce Training Grant in Strategic Training and Education in Power Systems through the University of Hawai' $i$ Renewable Energy and Island Sustainability (REIS) Center. We also acknowledge financial support for this research from the Ministry of Education, Science and Culture of Japan through a Grant-in-Aid for Scientific Research on Priority Areas entitled "Experimental Social Sciences: Toward Experimentally-based New Social Sciences for the 21st Century" and the Japan Society for the Promotion of Science through grant JSPS KAKENHI Grant Number 24243028. Special thanks to the electricians at the Office of Facilities and Grounds at the University of Hawai' $i$ at Mānoa, who helped us install the devices. Chaning Jang, Joshua Jensen, and Qianxue Zhao provided excellent research assistance. We also acknowledge helpful comments from Timothy Halliday, Inna Cintina, and seminar participants at various meetings including those organized by CREST (PI: Kenko Uchida) from Japan Science and Technology Agency. Anonymous referees' comments helped us improve the manuscript substantially. 


\section{References}

Abrahamse, W., Steg, L., Vlek, C., Rothengatter, T., 2005. A review of intervention studies aimed at household energy conservation. Journal of environmental psychology, 25(3), 273-291.

Agarwal, S., Driscoll, J.C., Gabaix, X., Laibson D., 2013. Learning in the Credit Card Market. Working Paper, Harvard University.

Allcott, H., Rogers, T., 2014. The Short-Run and Long-Run Effects of Behavioral Interventions: Experimental Evidence from Energy Conservation. American Economic Review, 104, 3003-37.

Asensio, O. I., Delmas, M. A., 2015. Nonprice incentives and energy conservation. Proceedings of the National Academy of Sciences, 201401880.

Attari, S. Z., DeKay, M. L., Davidson, C. I., de Bruin, W. B., 2010. Public perceptions of energy consumption and savings. Proceedings of the National Academy of Sciences, 107(37), 16054-16059.

Bertrand, M., Duflo, E., Mullainathan, S., 2004. How Much Should We Trust Differences-In-Differences Estimates? Quarterly journal of economics, 119(1), 249-275.

Chen, V. L., Delmas, M. A., Kaiser, W. J., 2014. Real-time, appliance-level electricity use feedback system: How to engage users?. Energy and buildings, 70, 455-462. 
Chen, V. L., Delmas, M. A., Kaiser, W. J., Locke, S. L., 2015. What can we learn from high-frequency appliance-level energy metering? Results from a field experiment. Energy Policy, 77, 164-175.

Deaton, A., 1997. The Analysis of Household Surveys: A Microeconometric Approach to Development Policy. Johns Hopkins University Press, Baltimore.

Delmas, M. A., Fischlein, M., Asensio, O. I., 2013. Information strategies and energy conservation behavior: A meta-analysis of experimental studies from 1975 to 2012. Energy Policy, 61, 729-739.

Delmas, M. A., Lessem, N., 2014. Saving power to conserve your reputation? The effectiveness of private versus public information. Journal of Environmental Economics and Management, 67(3), 353-370.

Dietz, T., 2010. Narrowing the US energy efficiency gap. Proceedings of the National Academy of Sciences, 107(37), 16007-16008.

Faruqui, A., Sergici, S., Sharif, A., 2010. The impact of informational feedback on energy consumption-A survey of the experimental evidence. Energy, 35(4), 1598-1608.

Fischer, C., 2008. Feedback on household electricity consumption: a tool for saving energy?. 
Energy Efficiency, 1(1), 79-104.

Gabaix, X., 2014. A Sparsity-Based Model of Bounded Rationality. Quarterly Journal of Economics, 129(4) 1661-1710.

Gillingham, K., Newell, R. G., Palmer, K., 2009. Energy Efficiency Economics and Policy. Annual Review of Resource Economics, 1(1), 597-620.

Haselhuhn, M.P, Pope, D.G., Schweitzer, M.E., Fishman P., 2012. The Impact of Personal Experience on Behavior: Evidence from Video-Rental Fines. Management Science 58(1): 52-61.

Houde, S., Todd, A., Sudarshan, A., Flora, J. A., Armel, K. C., 2013. Real-time Feedback and Electricity Consumption: A Field Experiment Assessing the Potential for Savings and Persistence. Energy Journal, 34(1).

Jessoe, K., Rapson, D. S., 2014. Knowledge is (Less) Power: Experimental Evidence from Residential Energy Use. American Economic Review, 104(4), 1417-1438.

Karlan, D., McConnell, M., Mullainathan, S., Zinman, J., 2015. Getting to the top of mind: How reminders increase saving. Management Science, forthcoming.

Leamer, E., 1978. Specification Searches: Ad hoc Inference with Non-Experimental Data. Wiley, New York. 
Matsukawa, I., 2004. The Effects of Information on Residential Demand for Electricity. Energy Journal, 25(1).

Midden, C. J., Meter, J. F., Weenig, M. H., Zieverink, H. J., 1983. Using feedback, reinforcement and information to reduce energy consumption in households: A field-experiment. Journal of Economic Psychology, 3(1), 65-86.

Mizobuchi, K., Takeuchi, K., 2012. Using Economic Incentives to Reduce Electricity Consumption: A field Experiment in Matsuyama, Japan. International Journal of Energy Economics and Policy, 2(4), 318-332.

Newell, R. G. \& Siikamäki, J. V., 2014. Nudging Energy Efficiency Behavior: The Role of Information Labels. Journal of the Association of Environmental and Resource Economists, 1(4), $555-598$.

Petersen, J. E., Shunturov, V., Janda, K., Platt, G., Weinberger, K., 2007. Dormitory residents reduce electricity consumption when exposed to real-time visual feedback and incentives. International Journal of Sustainability in Higher Education, 8(1), 16-33.

Sexton, R. J., Sexton, T. A., Wann, J. J. W., Kling, C. L., 1989. The Conservation and Welfare Effects of Information in a Time-of-Day Pricing Experiment. Land economics, 65(3). 
Winett, R. A., Kagel, J. H., Battalio, R. C., Winkler, R. C., 1978. Effects of monetary rebates, feedback, and information on residential electricity conservation. Journal of Applied Psychology, 63(1), 73 .

Wood, G., Newborough, M., 2003. Dynamic energy-consumption indicators for domestic appliances: environment, behaviour and design. Energy and Buildings, 35(8), 821-841.

Yates, S. M., Aronson, E., 1983. A social psychological perspective on energy conservation in residential buildings. American Psychologist, 38(4), 435. 
Figures and Tables

Figure 1. Average electricity consumption by group and by period

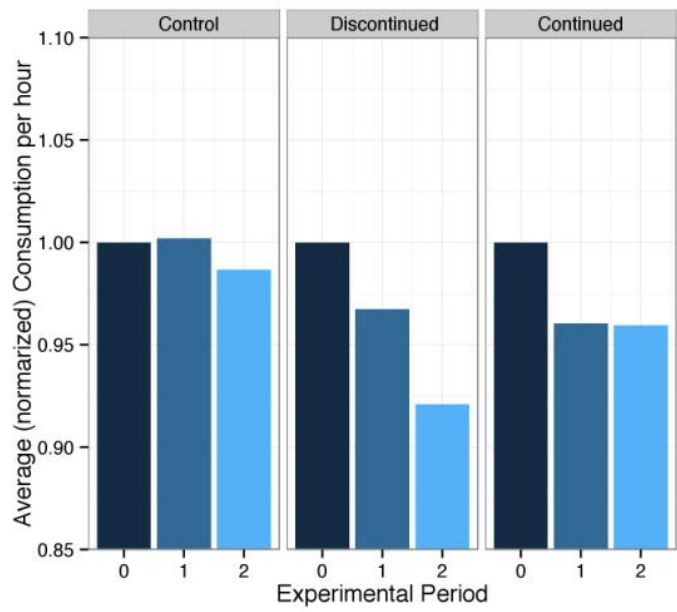

Figure 2. Average electricity consumption in the morning and in the evening
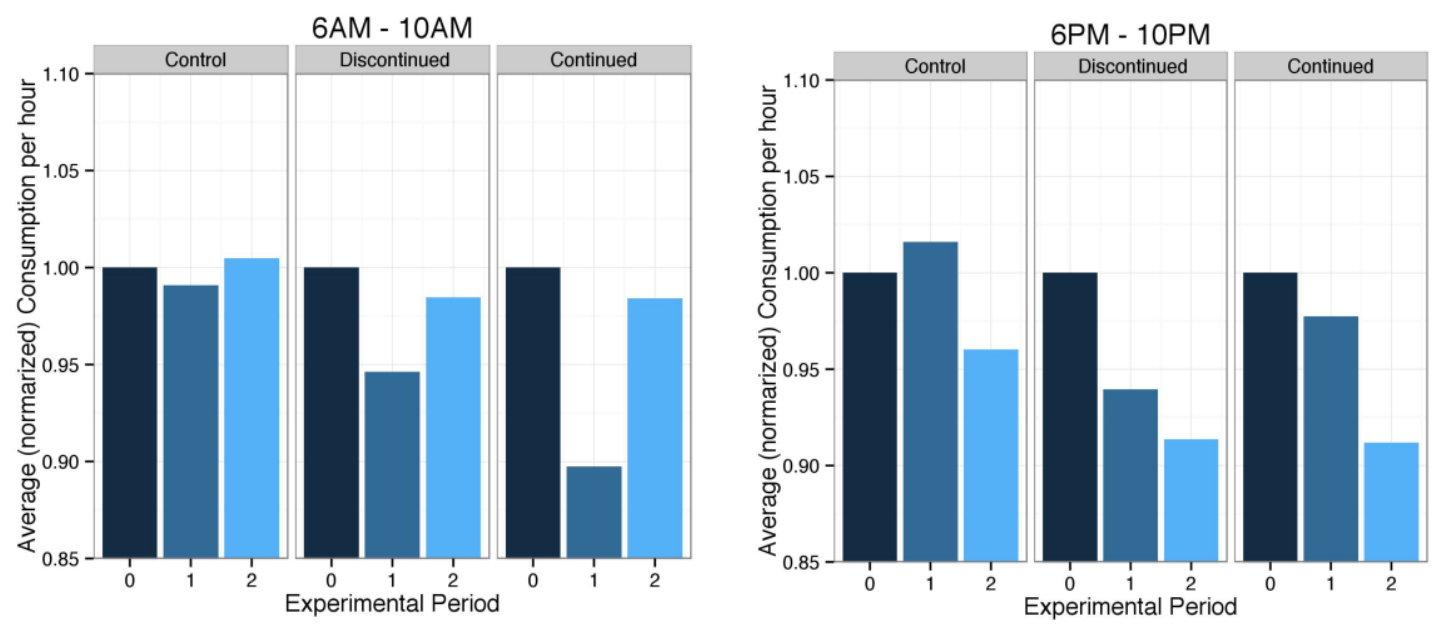
Figure 3. Survey Responses to the Question: How Much Energy Does This Device

\section{Consume?}

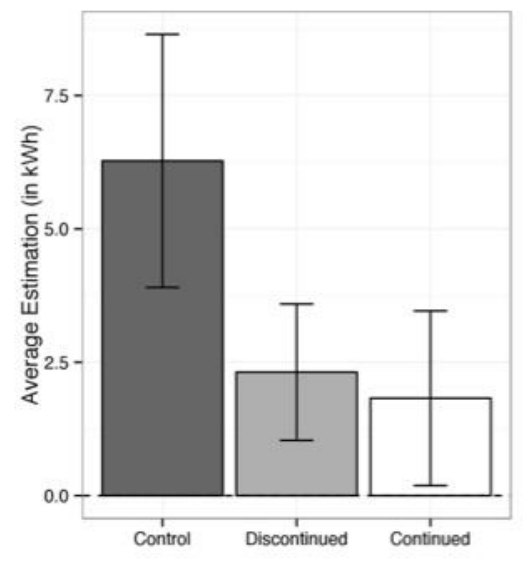

(a) Lamp

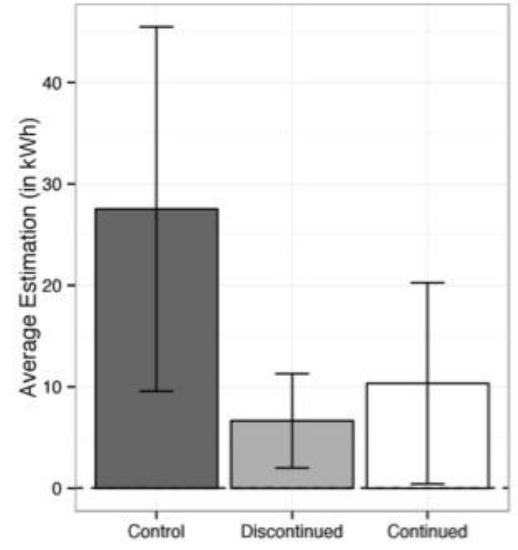

(c) Television

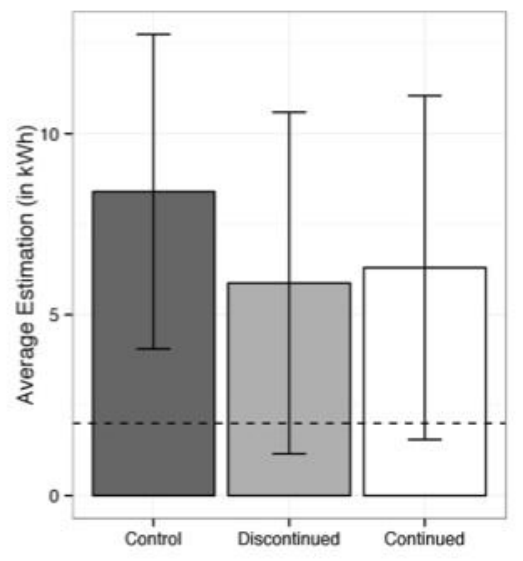

(b) Stovetop

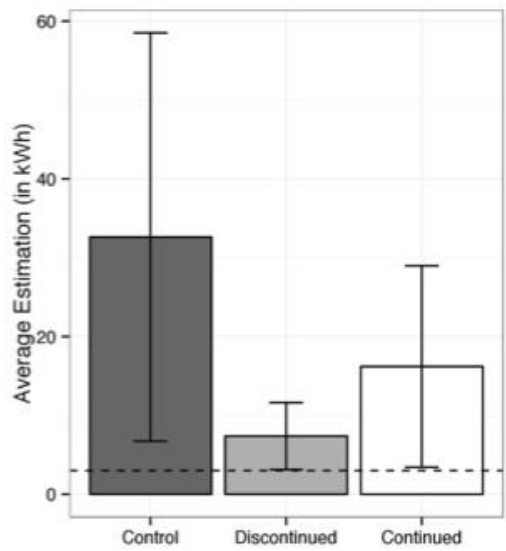

(d) Water-heater

Notes: Each column represents the mean survey response of how much each device consumes in terms of Kwh by treatment group. Bars represent estimated standard errors and the horizontal dashed lines represent how much each device actually consumes. 
Table 1. Experimental Design and Potential Effects

\begin{tabular}{llll}
\hline Group & Period 0 & Period 1 & Period 2 \\
\hline Control & $\begin{array}{l}\text { No Information } \\
\text { (No effect) }\end{array}$ & $\begin{array}{l}\text { No Information } \\
\text { (No effect) }\end{array}$ & $\begin{array}{l}\text { No Information } \\
\text { (No effect) }\end{array}$ \\
\hline Discontinued treatment & $\begin{array}{l}\text { No Information } \\
\text { (No effect) }\end{array}$ & $\begin{array}{l}\text { Receive Information } \\
\text { (L1 and S) }\end{array}$ & $\begin{array}{l}\text { No Information } \\
\text { (RL1) }\end{array}$ \\
\hline Continued treatment & $\begin{array}{l}\text { No information } \\
\text { (No effect) }\end{array}$ & $\begin{array}{l}\text { Receive Information } \\
\text { (L1 and S) }\end{array}$ & $\begin{array}{l}\text { Receive Information } \\
\text { (RL1, L2 and S) }\end{array}$ \\
\hline \hline
\end{tabular}

Notes: "No Information" means that the residents in the corresponding group receive no information beyond their monthly electricity bills. "Receive information" means that they have access to in-home displays, which provide additional real-time information. The potential treatment effects are in parentheses. "L1" means the learning effect occurring in Period 1, "S" means the saliency effect, "L2" means the learning effect occurring in Period 2, "RL1" means the remaining learning effect from Period 1.

Table 2. Characteristics of household participants

\begin{tabular}{lcccc} 
& Overall & Control & DT & CT \\
\hline \hline Age of the Respondent & 33.53 & 35.51 & 31.68 & 33.58 \\
& $(1.39)$ & $(2.95)$ & $(2.34)$ & $(1.97)$ \\
\hline \# of People in Each Household & 2.69 & 2.33 & 3.09 & 2.64 \\
& $(0.15)$ & $(0.25)$ & $(0.30)$ & $(0.22)$ \\
\hline \# of Children (under 18 years old) & 0.86 & 0.60 & 1.27 & 0.68 \\
& $(0.12)$ & $(0.17)$ & $(0.23)$ & $(0.17)$ \\
\hline \# of Income Earners & 1.48 & 1.40 & 1.41 & 1.64 \\
& $(0.07)$ & $(0.11)$ & $(0.11)$ & $(0.14)$ \\
\hline Hours at Home on Weekdays & 16.19 & 14.64 & 16.25 & 17.61 \\
& $(0.51)$ & $(0.89)$ & $(0.91)$ & $(0.80)$ \\
\hline Hours at Home on Weekends & 17.79 & 16.76 & 17.80 & 18.75 \\
& $(0.54)$ & $(1.04)$ & $(0.97)$ & $(0.76)$ \\
\hline Observations & 58 & 21 & 22 & 22 \\
\hline \hline
\end{tabular}

Notes: Standard errors in parentheses. DT: Discontinued treatment group, CT: Continued treatment group. 
Table 3. Average Electricity Consumption Per Hour (in kWh)

\begin{tabular}{|c|c|c|c|c|c|c|c|c|c|}
\hline Treatment & \multicolumn{3}{|c|}{ Control } & \multicolumn{3}{|c|}{ Discontinued treatment } & \multicolumn{3}{|c|}{ Continued treatment } \\
\hline Period & 0 & 1 & 2 & 0 & 1 & 2 & 0 & 1 & 2 \\
\hline Mean 6am-10am & 0.585 & 0.580 & 0.588 & 0.500 & 0.473 & 0.492 & 0.619 & 0.556 & 0.610 \\
\hline s.e. & 0.061 & 0.056 & 0.059 & 0.051 & 0.037 & 0.043 & 0.074 & 0.062 & 0.061 \\
\hline Mean 10am-6pm & 0.401 & 0.404 & 0.390 & 0.385 & 0.389 & 0.342 & 0.401 & 0.404 & 0.391 \\
\hline s.e. & 0.042 & 0.042 & 0.043 & 0.035 & 0.037 & 0.030 & 0.039 & 0.038 & 0.035 \\
\hline Mean 6pm-10pm & 0.671 & 0.682 & 0.644 & 0.791 & 0.743 & 0.723 & 0.663 & 0.648 & 0.604 \\
\hline s.e. & 0.074 & 0.072 & 0.071 & 0.093 & 0.084 & 0.082 & 0.066 & 0.051 & 0.044 \\
\hline Mean 10pm-6am & 0.286 & 0.296 & 0.299 & 0.243 & 0.251 & 0.243 & 0.264 & 0.257 & 0.262 \\
\hline s.e. & 0.032 & 0.032 & 0.035 & 0.025 & 0.021 & 0.021 & 0.022 & 0.018 & 0.020 \\
\hline Mean Daily & 0.442 & 0.443 & 0.437 & 0.432 & 0.418 & 0.398 & 0.438 & 0.421 & 0.420 \\
\hline s.e. & 0.039 & 0.038 & 0.040 & 0.035 & 0.034 & 0.032 & 0.037 & 0.031 & 0.031 \\
\hline No. of Households & 17 & 18 & 18 & 13 & 18 & 19 & 17 & 20 & 20 \\
\hline
\end{tabular}


Table 4. IHD Regression Results

\begin{tabular}{ccccccc}
\hline \hline & $(1)$ & $(2)$ & $(3)$ & $(4)$ & $(5)$ & $(6)$ \\
Observations & 1AM-6AM & 6AM-10AM & 10AM-6PM & 6PM-10PM & 10PM-1AM & Daily \\
\hline All Periods & -0.0011 & -0.0461 & 0.012 & $-.0748^{*}$ & 0.032 & -0.0189 \\
& $(0.0272)$ & $(0.0476)$ & $(0.0379)$ & $(0.0443)$ & $(0.0397)$ & $(0.0291)$ \\
Periods 0 \& 1 & 0.0126 & $-0.112^{*}$ & 0.010 & -0.056 & 0.0358 & -0.0254 \\
& $(0.0373)$ & $(0.0654)$ & $(0.0431)$ & $(0.0531)$ & $(0.0436)$ & $(0.0294)$ \\
\hline \hline
\end{tabular}

Notes: Bootstrapped standard errors in parentheses, $* \mathrm{p}<.10$, ** $\mathrm{p}<.05, * * * \mathrm{p}<.01$. The regressions include household and day fixed effects. 
Table 5. Hourly treatment effects.

\begin{tabular}{|c|c|c|c|c|c|c|}
\hline \multirow[t]{2}{*}{ Hour } & \multicolumn{3}{|c|}{ All Periods } & \multicolumn{3}{|c|}{ Periods 0 and 1} \\
\hline & Estimate & & s.e. & Estimate & & s.e. \\
\hline 1 & -0.050 & & $(0.047)$ & -0.043 & & $(0.056)$ \\
\hline 2 & -0.030 & & $(0.043)$ & -0.009 & & $(0.026)$ \\
\hline 3 & 0.031 & & $(0.040)$ & 0.050 & & $(0.026)$ \\
\hline 4 & 0.036 & & $(0.037)$ & 0.028 & & $(0.024)$ \\
\hline 5 & 0.094 & $* *$ & $(0.046)$ & 0.111 & $* *$ & $(0.028)$ \\
\hline 6 & 0.020 & & (0.094) & -0.053 & & $(0.039)$ \\
\hline 7 & -0.040 & & $(0.073)$ & -0.071 & & $(0.042)$ \\
\hline 8 & -0.051 & & $(0.079)$ & -0.063 & & $(0.041)$ \\
\hline 9 & -0.027 & & $(0.091)$ & -0.105 & & $(0.040)$ \\
\hline 10 & 0.001 & & $(0.061)$ & -0.017 & & $(0.038)$ \\
\hline 11 & 0.000 & & $(0.051)$ & -0.020 & & $(0.035)$ \\
\hline 12 & 0.019 & & (0.049) & 0.005 & & $(0.035)$ \\
\hline 13 & 0.016 & & $(0.053)$ & 0.027 & & $(0.034)$ \\
\hline 14 & 0.011 & & $(0.048)$ & 0.004 & & $(0.032)$ \\
\hline 15 & 0.001 & & $(0.046)$ & 0.007 & & $(0.034)$ \\
\hline 16 & -0.004 & & $(0.044)$ & 0.002 & & $(0.034)$ \\
\hline 17 & 0.017 & & $(0.069)$ & 0.089 & & $(0.038)$ \\
\hline 18 & -0.118 & $* *$ & $(0.056)$ & -0.093 & & $(0.034)$ \\
\hline 19 & -0.085 & & $(0.053)$ & -0.060 & & $(0.035)$ \\
\hline 20 & -0.044 & & (0.061) & -0.015 & & $(0.032)$ \\
\hline 21 & 0.056 & & $(0.054)$ & 0.118 & & $(0.034)$ \\
\hline 22 & 0.024 & & $(0.045)$ & 0.036 & & $(0.033)$ \\
\hline 23 & 0.040 & & $(0.042)$ & 0.057 & & $(0.032)$ \\
\hline 24 & -0.042 & & $(0.055)$ & -0.065 & & $(0.030)$ \\
\hline
\end{tabular}

Notes: Standard errors are bootstrapped, $* \mathrm{p}<.10, * * \mathrm{p}<.05, * * * \mathrm{p}<.01$. The regressions include household, daily, and hourly fixed effects. 
Table 6. Learning and Saliency effects (in the morning peak, 6AM-10AM)

(a) Control vs. Discontinued Treatment

Week 1

Week 2

Week 3

Week 4+

\begin{tabular}{rrc} 
Estimate & & s.e. \\
\hline-0.1430 & $* *$ & $(0.0666)$ \\
-0.0866 & & $(0.1021)$ \\
-0.0832 & & $(0.0604)$ \\
0.0575 & & $(0.0955)$
\end{tabular}

(b) Control vs. Discontinued vs. Continued Treatment

IHD (period 1)

Discontinuous Treatment

Continuous Treatment

\begin{tabular}{ccc} 
Estimate & & s.e. \\
\hline-0.1265 & $* *$ & $(0.0614)$ \\
-0.0604 & & $(0.0789)$ \\
-0.0254 & & $(0.0605)$ \\
\hline
\end{tabular}

Notes: Bootstrapped standard errors in parentheses, $* \mathrm{p}<.10, * * \mathrm{p}$ $<.05, * * * \mathrm{p}<.01$. 
Table 7. Further evidence for learning and saliency effects

\begin{tabular}{|c|c|c|c|c|}
\hline Treatment & \multicolumn{2}{|c|}{ (1) $6 \mathrm{AM}-10 \mathrm{AM}$} & \multicolumn{2}{|c|}{ (2) 6PM-9PM } \\
\hline \multicolumn{5}{|l|}{$\underline{\text { Period } 1}$} \\
\hline Week 1 & -0.0511 & $(0.0808)$ & -0.044 & $(0.0819)$ \\
\hline Week 2 & $-0.1505 * *$ & $(0.0658)$ & -0.076 & $(0.0723)$ \\
\hline Week 3 & $-0.2234^{* * *}$ & $(0.0801)$ & $-0.154 *$ & $(0.0865)$ \\
\hline Week 4 & $-0.1527 *$ & $(0.0865)$ & -0.067 & $(0.0982)$ \\
\hline Week 5 & -0.0719 & $(0.1365)$ & -0.139 & $(0.1189)$ \\
\hline Week 6 & -0.1712 & $(0.1334)$ & -0.118 & $(0.0971)$ \\
\hline
\end{tabular}

Period 2, Discontinued treatment

$\begin{array}{llccr}\text { Week } 1 & -0.1405 * * & (0.0689) & 0.0478 & (0.0960) \\ \text { Week 2 } & -0.0947 & (0.0947) & -0.0177 & (0.1166) \\ \text { Week 3 } & -0.0807 & (0.0949) & 0.0604 & (0.1306) \\ \text { Week 4+ } & 0.0554 & (0.1250) & -0.0034 & (0.1311) \\ \chi^{2} & 11.57(\mathrm{p}=0.02) & 1.96(\mathrm{p}=0.74)\end{array}$

Period 2, Continued treatment

$\begin{array}{lllrl}\text { Week 1 } & -0.0649 & (0.0825) & -0.0102 & (0.0866) \\ \text { Week 2 } & -0.0281 & (0.0966) & -0.0489 & (0.1122) \\ \text { Week 3 } & -0.0089 & (0.0663) & 0.0118 & (0.1160) \\ \text { Week 4+ } & -0.0199 & (0.0878) & -0.1357 & (0.1192)\end{array}$

$\chi^{2} \quad 0.70(\mathrm{p}=0.95) \quad 4.68(\mathrm{p}=0.32)$

Notes: Bootstrapped standard errors in parentheses, $* \mathrm{p}<.10, * * \mathrm{p}<.05$, $* * * \mathrm{p}<.01 . \chi^{2}$ refers to the $\chi^{2}$ value for the hypotheses $\beta_{2 h w}=0$ for all $w$ under each treatment. 
Table 8. Evidence for learning and saliency effects (by hour in the morning)

\begin{tabular}{|c|c|c|c|c|c|c|c|c|}
\hline Period 1 & \multicolumn{2}{|c|}{$6 \mathrm{am}$} & \multicolumn{2}{|c|}{$7 \mathrm{am}$} & \multicolumn{2}{|c|}{$8 \mathrm{am}$} & \multicolumn{2}{|c|}{ 9am } \\
\hline Week 1 & 0.0560 & $(0.1322)$ & 0.0420 & $(0.1148)$ & -0.0665 & $(0.1014)$ & -0.1839 & $(0.1146)$ \\
\hline Week 2 & -0.1042 & $(0.1130)$ & -0.0791 & $(0.1119)$ & -0.1430 & $(0.1100)$ & -0.0876 & $(0.1156)$ \\
\hline Week 3 & $-0.2882 * *$ & $(0.1298)$ & $-0.2008 *$ & $(0.1138)$ & -0.1248 & $(0.1125)$ & -0.1051 & $(0.1328)$ \\
\hline Week 4 & -0.1312 & $(0.1173)$ & -0.0291 & $(0.1153)$ & -0.0446 & $(0.1186)$ & -0.0685 & $(0.1391)$ \\
\hline Week 5 & -0.1571 & $(0.1459)$ & -0.1981 & $(0.1590)$ & 0.0740 & $(0.1342)$ & 0.0956 & $(0.1461)$ \\
\hline Week 6 & 0.0080 & $(0.1725)$ & -0.0815 & $(0.1569)$ & -0.0583 & $(0.1441)$ & $-0.3036 *$ & (0.1738) \\
\hline
\end{tabular}

$\underline{\text { Period 2, discontinued treatment }}$

$\begin{array}{lccccccrr}\text { Week 1 } & -0.2949 * & (0.1785) & -0.1194 & (0.1114) & -0.1023 & (0.1254) & 0.0124 & (0.1335) \\ \text { Week 2 } & -0.0585 & (0.1345) & -0.0287 & (0.1343) & -0.1013 & (0.1195) & -0.0535 & (0.1633) \\ \text { Week 3 } & 0.0340 & (0.1580) & -0.0232 & (0.1142) & 0.0954 & (0.1534) & -0.1744 & (0.1525) \\ \text { Week 4+ } & -0.0491 & (0.1540) & 0.0257 & (0.1905) & 0.1784 & (0.1857) & -0.0209 & (0.1612) \\ \chi^{2} & 14.84(\mathrm{p}=0.005) & 2.40(\mathrm{p}=0.66) & 4.88(\mathrm{p}=0.30) & 4.64(\mathrm{p}=0.33)\end{array}$

Period 2, continued treatment

\begin{tabular}{lllllllll} 
Week 1 & 0.1772 & $(0.1409)$ & -0.1295 & $(0.1125)$ & $-0.2004 *$ & $(0.1297)$ & 0.0041 & $(0.1414)$ \\
Week 2 & 0.1634 & $(0.1531)$ & -0.0961 & $(0.1243)$ & -0.1068 & $(0.1590)$ & -0.0099 & $(0.1589)$ \\
Week 3 & $0.2509 *$ & $(0.1498)$ & 0.1456 & $(0.1175)$ & -0.0856 & $(0.1252)$ & -0.0712 & $(0.1466)$ \\
Week 4+ & 0.1429 & $(0.1745)$ & -0.0760 & $(0.1204)$ & -0.1005 & $(0.1557)$ & -0.0934 & $(0.1451)$ \\
$\chi^{2}$ & $3.32(\mathrm{p}=0.51)$ & $9.03(\mathrm{p}=0.06)$ & $2.65(\mathrm{p}=0.62)$ & $1.28(\mathrm{p}=0.86)$ \\
\hline $\begin{array}{l}\text { Notes: Bootstrapped standard errors in parentheses, } * \mathrm{p}<.10, * * \mathrm{p}<.05, * * * \mathrm{p}<.01 . \chi^{2} \text { refers to the } \chi^{2} \\
\text { value for the hypotheses }\end{array}$ \\
$\beta_{2 h w}=0$ for all $w$ for each hour $h$ under each treatment.
\end{tabular}

